\title{
Effect of surface adsorption on icing behaviour of metallic coating
}

\author{
Jie Wanga, Halar Memon ${ }^{\mathrm{a}}$, Junpeng Liu ${ }^{\mathrm{a}}$, Guang Yang ${ }^{\mathrm{b}}$, Fang Xu' ${ }^{\mathrm{a}}$, Tanvir Hussain ${ }^{\mathrm{a}}$, Colin \\ Scotchford $^{\mathrm{a}}$ and Xianghui $\mathrm{Hou}^{\mathrm{a} *}$ \\ ${ }^{a}$ Faculty of Engineering, University of Nottingham, University Park, Nottingham NG7 2RD, UK; \\ ${ }^{\mathrm{b}}$ Key Laboratory of Aerospace Materials and Performance (Ministry of Education), School of Materials \\ Science and Engineering, Beihang University, Beijing 100191, China \\ * Correspondence: xianghui.hou@ nottingham.ac.uk; Tel: +44-115-95-13920
}

\begin{abstract}
Icephobicity of materials has received intensive attention in recent years due to the increasing requirement of ice protection in aerospace, wind energy and power lines. However, the influencing factors of material icephobicity have not been well identified. In this work, the effect of surface gaseous adsorption on icing behaviour of materials was investigated for the first time. $\mathrm{Ni}-\mathrm{Cu}-\mathrm{P}$ coatings with different surface morphologies were fabricated and used as the objects of the study. Environmental scanning electron microscopy (ESEM) was utilized to observe the water condensation and ice formation on the coatings. X-ray photoelectron spectroscopy (XPS) was employed to analyse the variations of surface adsorption. Droplets icing time and ice adhesion strength of the coatings were also studied. The results showed that the icing time of water droplets on the $\mathrm{Ni}-\mathrm{Cu}-\mathrm{P}$ coatings increased significantly, and the ice adhesion strength decreased sharply with the spontaneous surface adsorption of gaseous species (mainly hydrocarbon groups) in air. The adsorbed hydrocarbon species would promote the formation of air pockets between the ice-coating interface, which could effectively reduce the interfacial contact of the formed ice with the coating. When the adsorbed hydrocarbon species were removed by plasma cleaning, water droplets tended to have more direct contacts with the coatings prior to icing, leading to the formation of interlocked ice and significantly increased the ice adhesion on the surface. The variation of surface icephobicity can also be attributed to the changes of surface energy due to the surface adsorption. The results indicated that the surface
\end{abstract}


gaseous adsorption in air played an important role in determining the surface icing behaviour and the icephobicity of the materials.

Key Words: Surface adsorption; Icephobicity; Ni-Cu-P ternary coating; Interfacial contact; Interlocked ice.

\section{Introduction}

Formation, accretion and adhesion of ice, snow or their mixtures could cause serious socio-economic impacts in daily life and could even lead to catastrophic failures in certain situations [1]. Icephobicity of materials has received intensive attention in the last decade due to the increasing requirement of ice protection in aerospace, wind energy and power lines [2, 3]. Some reports suggest that surface hydrophobicity can be applied to design the icephobic coatings due to the capability of water repellency and freezing delay [4, 5]. Zheng et al. fabricated superhydrophobic aluminum surface with hierarchical micro/nano structure by anodization method which had a water contact angle (WCA) of $156^{\circ}$, exhibiting a delay in ice formation and low ice adhesion strength of $40 \mathrm{KPa}$ [6]. Wang et al. reported that superhydrophobic steel surface prepared by chemical etching process demonstrated excellent anti-icing properties [7]. However, the influencing factors on material icephobicity have not been well identified. In certain circumstances, the hierarchical surface that is necessary for hydrophobicity could increase the ice adhesion strength which is contradictory for icephobic applications [8].

Considering the icephobicity of materials surface, it often refers to the capability of delaying the ice nucleation and growth [9], as well as the "non-stick" feature - low ice adhesion [10]. It is believed that icephobicity of a material surface is affected by many factors: surface condition, relative humidity of atmosphere [11], liquid water content [12], and mechanical adhesion [13], etc. Among them, the surface condition could be one of the dominating factors. Some recent work demonstrated that the surface gaseous adsorption on the material surface could 
have significant impacts on surface condition, reflected by the change of wettability $[14,15]$. Feng et al. reported a reversible conversion of surface wettability on aligned $\mathrm{ZnO}$ nanorod films caused by the adsorption and desorption of surface hydroxyl groups using UV illumination and dark storage, respectively [16]. Archana et al. found that plasma treated $\mathrm{CuO} / \mathrm{Cu}(\mathrm{OH})_{2}$ exhibited reversible wettability transition because of the surface adsorption [17]. However, there is a lack of direct investigation on the effect of surface gaseous adsorption on the material icephobicity. Moreover, the study on the effect of surface gaseous adsorption could also help to establish universal and repeatable testing standards when evaluating the material icephobicity, which is also a critical issue for the development of icephobic coatings and surfaces.

The role of surface adsorption on surface wettability has been confirmed in our previous work on electrodeposited $\mathrm{Ni}-\mathrm{Cu}-\mathrm{P}$ ternary coating with the help of plasma cleaning and surface analysis [18]. The wettability of the $\mathrm{Ni}-\mathrm{Cu}-\mathrm{P}$ coating changed significantly with spontaneous surface adsorption in air. In the current work, the effect of surface gaseous adsorption on icing behaviour was investigated for the first time. $\mathrm{Ni}-\mathrm{Cu}-\mathrm{P}$ ternary coating was selected as the objects of the study due to its sensitivity on surface gaseous adsorption with ageing time. The results indicated the importance of the surface gaseous adsorption in determining the icing behaviour and surface icephobicity of the Ni-Cu-P ternary coating.

\section{Experiment section}

\subsection{Materials}

Nickel sulfate hexahydrate, copper sulfate pentahydrate and sodium dihydrogen phosphate from Sigma-Aldrich (Dorset, UK) were used as the starting chemicals of nickel, copper and phosphorus, respectively. Other agents including sodium citrate dihydrate, ammonium chloride, succinic acid, sodium acetate, sodium molybdate, tin (II) chloride, palladium (II) chloride, citric acid, sodium dodecyl sulfate (SDS) and sodium sulfate $\left(\mathrm{Na}_{2} \mathrm{SO}_{4}\right)$ were also acquired from Sigma-Aldrich. 304 stainless steel (SS) plates were used as the 
substrates. Nickel foil (Shenzhen Changsheng Telecom Technology Co. Ltd, China, 99.96\%) was applied as the anode of electrodeposition.

\subsection{Coating fabrication}

The substrates were cut into rectangular pieces with dimensions of $50 \mathrm{~mm} \times 20 \mathrm{~mm} \times 1$ mm. Sand-blasting treatment was conducted with 220 grit white alumina, for the aim of enhancing the mechanical bonding of the coating on the substrates. For electroless deposition, a two-step pre-treatment was performed before electroless deposition process to form catalytic seeds. The substrates were immersed into a solution of $0.1 \mathrm{~mol} / \mathrm{L} \mathrm{SnCl}_{2}$ and $0.1 \mathrm{~mol} / \mathrm{L}$ of hydrochloric acid at room temperature for 30 min followed by washing using deionized water. After that, they were immersed into a mixture of $0.0014 \mathrm{~mol} / \mathrm{L} \mathrm{PdCl}_{2}, 0.25 \mathrm{~mol} / \mathrm{L} \mathrm{HCl}$ solution for another $30 \mathrm{~min}$ at room temperature. Then the substrates were ultrasonically cleaned for 10 min in deionized water. The electrolyte for electroless deposition consisted of $22.6 \mathrm{~g} / \mathrm{L} \mathrm{NiSO}_{4}$, $0.5 \mathrm{~g} / \mathrm{L} \mathrm{CuSO}_{4}, 26.1 \mathrm{~g} / \mathrm{L}$ sodium citrate dihydrate, $40 \mathrm{~g} / \mathrm{L} \mathrm{NH} 4 \mathrm{Cl}, 5 \mathrm{~g} / \mathrm{L}$ succinic acid, $5 \mathrm{~g} / \mathrm{L}$ sodium acetate and $5 \times 10^{-6} \mathrm{~g} / \mathrm{L} \mathrm{Na}_{2} \mathrm{MoO}_{4}$. The $\mathrm{pH}$ value was maintained at around 5.0 5.3. The deposition temperature was controlled by a hot plate at around $90{ }^{\circ} \mathrm{C}$. Magnetic stirring was utilized to ensure the uniformity of the electrolyte with an agitation speed at $100 \mathrm{rpm}$. The electroless deposition process was $30 \mathrm{~min}$. For the electrodeposition, the coating was fabricated using the well-stirred electrolyte with pH 5.5, current density $50 \mathrm{~mA} / \mathrm{cm}^{2}$ at $25^{\circ} \mathrm{C}$ with a duration of 30 mins [18].

After the electroless deposition and electrodeposition process, the samples were washed using deionized water and further dried by compressed air. The coatings prepared by electroless deposition and electrodeposition methods were designated as ELD and ED, respectively. For the ageing process, the samples were stored indoor in ambient air condition. The relative humidity was around $45 \pm 10 \%$, and the ambient temperature was $20 \pm 3{ }^{\circ} \mathrm{C}$. In order to eliminate the possible surface adsorption from the air, plasma cleaning was conducted for 8 mins using a 
Plasma Cleaner (Model 1020, Fischione). The plasma gas consisted of 25 vol\% oxygen and 75 vol\% argon.

\subsection{Microstructural characterisation}

Surface morphology of the Ni-Cu-P ternary coatings was characterized using a JEOL6490LV scanning electron microscopy (SEM). The coating phases were identified by a Siemens D500 X-ray diffraction (XRD) system. The surface compositions and binding energy of the related elements were characterized by an X-ray photoelectron spectroscopy (XPS) (Kratos Analytical Limited). Then the results were further analysed by CasaXPS software. 3D topography of the coating surfaces was acquired by a non-contact optical profiler (Zeta-20, KLATencor).

\subsection{Observation of water condensation and ice formation}

In-situ water condensation and ice formation process was studied by an environmental scanning electron microscopy (ESEM) equipped with a Peltier cooling stage (FEI Quanta 650, ThermoFisher). With a differential pumping system and a gaseous secondary electron detector (GSED), hydrated samples could be imaged. During the ESEM observation, the water vapour pressure of the chamber and the temperature of the cooling stage could be adjusted, which would help the water condensation on the sample surface. In this work, the water condensation and ice formation process of the coating surface before plasma cleaning and after plasma cleaning were analyzed, respectively. The observation on water condensation process was operated in a controlled environment at temperature of $2.0 \pm 1.0^{\circ} \mathrm{C}$ and relative humidity of $95 \pm 5 \%$, while in the observation of ice formation process, the temperature was set to $-5.0 \pm 2.0^{\circ} \mathrm{C}$ with relative humidity of $95 \pm 5 \%$.

\subsection{Wettability and icephobicity evaluation}


An FTA200 contact angle goniometer (First Ten Angstroms, Inc.) was used to evaluate the hydrophobicity of the coating surfaces with water flow rate of $1 \mu \mathrm{L} / \mathrm{s}$ at room temperature.

Droplet icing test was carried out by determining the duration of ice formation from water droplets with a volume of $4 \mu \mathrm{L}$ on five different points on the coated samples and the substrates for comparison on a cold plate at $-10{ }^{\circ} \mathrm{C}$. By video recording the icing of water droplets, the icing times of the coatings were obtained.

Ice adhesion strengths of the coating surface were tested using a centrifuge system with an ice block attached to the coating surface in an environmental chamber at $-10^{\circ} \mathrm{C}$. With a certain value of acceleration of rotation, the glaze ice block would overcome the shear strength and detach from the sample. Then the ice adhesion strength could be determined from the mass of ice block and the length of the rotor arm [19].

$$
F=m r \omega^{2}
$$

Where $F$ refers to centrifugal force $(\mathrm{N}), m$ is the mass of ice block $(\mathrm{kg}), r$ is the beam radius $(\mathrm{m})$, and $\omega$ is the rotation speed $(\mathrm{rad} / \mathrm{s})$. From the centrifugal force, the shear strength of the ice on the coating could be calculated:

$$
\tau=F / A
$$

Where $\mathrm{A}$ is the contact area of the ice block on the coating $\left(\mathrm{m}^{2}\right)$, and $\tau$ is the shear strength $(\mathrm{Pa})$. Several samples were tested for better accuracy.

\subsection{Measurement of surface energy}

The surface energy of the coating is an important parameter for the icephobic surface. In this work, Owens-Wendt method was applied to measure the surface energy of the ED and ELD coatings [20]. In this method, it is assumed that the total surface free energy is the sum of the 
two components: dispersion components and polar components. Three liquids included distilled water, formamide and methylene iodide were employed to determine the surface energy. The measurement was conducted under atmospheric condition at temperature of $20{ }^{\circ} \mathrm{C}$.

\section{Results and discussion}

\subsection{XRD analysis of the coatings}

Fig. 1 shows XRD patterns of the stainless steel substrate, ED and ELD Ni-Cu-P coatings. The amorphous phosphorus could contribute to the broad peak positioned at $2 \theta$ around $44^{\circ}$ of the coatings, which remains stable before and after the plasma cleaning [21]. For ED coatings, a relatively intensive and sharp peak is found at $2 \theta$ of $44.6^{\circ}$, and it matches quite well with the $\mathrm{Ni}$ face-centred cubic (fcc) (111) peak (JCPDS \# 04-0850) [22]. While for ELD coating, the strong sharp peak at $2 \theta$ of $43.7^{\circ}$ could be assigned as the (111) peak of $\mathrm{Cu}_{0.81} \mathrm{Ni}_{0.19}$ (JCPDS \# 47-1406) [23], which indicates the predominance of copper-nickel phase. Here, $\mathrm{Cu}_{0.81} \mathrm{Ni}_{0.19}$ (around 3.59 $\AA$ ) is the solid solution of copper in nickel, as nickel and copper are fully soluble. For the lattice

parameter of pure Ni and pure Cu (JCPDS \# 65-9743), they are $3.524 \AA$ and $3.615 \AA$, respectively. While for $\mathrm{Cu}_{0.81} \mathrm{Ni}_{0.19}$, the calculated lattice parameter is between these two values. All of the diffraction patterns consist of two relatively low peaks at $50.6^{\circ}$ and $74.7^{\circ}$. These peak positions are close to the (200) and (220) diffraction of the austenite phase in the substrate [24]. The broader peaks indicate the existence of additional phase with finer grain size. Regarding the ED coating, the two peaks could be the (200) and (220) for another fcc $\mathrm{NiCu}$ phase [18]. While for ELD coatings, these peaks match with the (200) and (220) peaks of $\mathrm{Cu}_{0.81} \mathrm{Ni}_{0.19}$ phase. The diffraction peaks of ELD coatings at around $44.7^{\circ}$ matches the (111) peaks for fcc Ni at $44.5^{\circ}$. Both $\mathrm{Ni}$ and $\mathrm{Cu}_{0.81} \mathrm{Ni}_{0.19}$ phases remain unchanged with plasma treatment, and no new phase forms. 


\subsection{Surface morphology of the coatings}

Fig.2 (a) shows the SEM surface morphology of the as-deposited ELD coating. The coating surface exhibits a quite flat and smooth structure which is made up of spherical nodular deposits tightly connected to each other. There are also some coarse nodular structures distributed on the surface. The co-deposited copper ions in the ELD electrolyte play an important role in activating natural nucleation points and slowing down the nodule growth. Also, the copper ion concentration during the electroless deposition is in a medium level that produces the less hierarchical surface microstructure [22]. The top-right enlarged image indicates that the size of the nodular structures is within the scope of $1 \mu \mathrm{m}$ to $5 \mu \mathrm{m}$. The coating covers the substrate quite well. Fig.2 (b) is the three-dimensional surface topography. The surface roughness Ra measured by the surface profiler is about $0.50 \pm 0.02 \mu \mathrm{m}$. It is clear that the extruded nodules appear on the surface. The yellow bulges represent the spherical nodular structures as indicated before. Fig. 2 (c) presents the SEM surface morphology of the ED coating. The hierarchical cauliflower-like structure is clearly observed. The top-right enlarged image shows that the size of the sphere is within a range between $300 \mathrm{~nm}$ and $500 \mathrm{~nm}$, while the cauliflower-like structures are in a micronscale range. Fig.2 (d) shows the 3D surface topography image. The measured average Ra is about $3.83 \pm 0.12 \mu \mathrm{m}$. The red parts indicate the cauliflower-like structure which is in line with the former SEM images. The ELD coating is much smoother than the ED coating. With no obvious hierarchical structure, it means less specific surface area. The rugged structure could help to increase the specific surface area on the coatings and would further contribute to the changes of surface wettability. The difference could lead to the variation in the transition from hydrophilic to hydrophobic and the WCA recovery after plasma cleaning. Both the surface morphology and surface roughness of the ELD and ED remain unchanged with plasma cleaning.

\subsection{Wettability of the Ni-Cu-P ternary coatings}


Fig.3 (a) presents the evolution of WCA versus ageing duration of the as-deposited ELD coating. When storing in the ambient air, the WCA keeps increasing, from less than $20^{\circ}$ to around $100^{\circ}$. It takes around $9 \mathrm{~h}$ to change from hydrophilic to hydrophobic. After that, the WCA continues increasing and stabilizes at about $100^{\circ}$ after $18 \mathrm{~h}$. For ED coating, a similar increasing trend is observed, but the difference is that it takes around $60 \mathrm{~h}$ for the WCA to rise to nearly $140^{\circ}$. The variation of WCA change between ELD and ED could be mainly attributed to the difference of coating surface roughness: first, high surface roughness could bring large surface specific area, and the hierarchical cauli-flower structure would provide more adsorption sites which increase the gaseous adsorption [25]. Second, the surface chemistry and charge characteristic also affect the adsorption process. There are more $\mathrm{Cu}$ and $\mathrm{P}$ elements on ELD coating than ED coating, which might also increase the amount of hydrophilic groups on the surface [26]. The WCA increasing rate of ELD coating is much faster than that of the ED coating. The gaseous adsorption may take less time to finish the process of replacing, inserting into and/ or covering the formerly adsorbed hydrophilic groups on a smoother surface. However, the ED coatings possess better hydrophobicity at the end caused by a larger amount of gaseous adsorption than ELD coatings due to the complex surface structure.

Fig.3 (b) elucidates the WCA evolution of as-deposited ELD coating versus plasma cleaning. The coating surfaces could be cleaned by removing the adsorbed substances via the plasma treatment, without altering the surface structural characteristics and elemental compositions. Due to the very low energy, no sputtering or etching is involved [27], the surface morphologies of ELD and ED remained unchanged. After plasma cleaning, the samples are restored in ambient air, and the time-dependent wettability is observed again. Just after the plasma cleaning, the WCA suffers a sharp decrease from over $100^{\circ}$ to about $20^{\circ}$. After that, the measured WCA rises again and nearly recovers after around $32 \mathrm{~h}$. The wettability change in ELD coating is similar to the wettability transition of the ED coating which has been previously reported [18]. 
The removal of adsorbed gas species could well explain the decrease of WCA after plasma cleaning. The ELD coating may initially present high surface energy and demonstrate hydrophilic characteristic [28]. After being re-stored in ambient air, the adsorption process occurs again, so that the coatings eventually demonstrates recovery of WCA. The variation in recovery rate between ELD and ED lies in the surface roughness and surface composition. The ED coating has higher surface roughness and more hierarchical structure, which might slow down the replacement of hydrophilic groups during the recovery period. While for ELD coating, with smoother surface structure and lower surface roughness, the surface adsorbed groups could be replaced more easily, and the surface changes back to the hydrophobic state accordingly.

The surface energy on both ED and ELD coatings (aged in ambient air and after plasma cleaning) have been determined using Owens-Wendt method, as given in Tab. 1. The surface energy of ED coating aged in ambient air was only $28.3 \mathrm{~mJ} / \mathrm{m}^{2}$. The low surface energy would be ascribed to the adsorbed airborne hydrocarbons, which helped with the low ice adhesion strength. After plasma cleaning, the surface energy increased to $72.70 \mathrm{~mJ} / \mathrm{m}^{2}$, which was much higher than the value before the plasma cleaning. The reason could be the removal of the adsorbed hydrocarbons and oxygen gaseous species. Regarding ELD coating, the surface energy was $35.54 \mathrm{~mJ} / \mathrm{m}^{2}$ for samples aged in ambient air, and the value increased to $69.23 \mathrm{~mJ} / \mathrm{m}^{2}$ after plasma cleaning. The reason here was fairly similar to ED coating. The results confirms that the decrease of surface energy occur with the surface gasous adsorption, contributing to the changes of wettability.

\subsection{XPS surface analysis}

Fig.4 presents high-resolution XPS analysis of $\mathrm{C}$ 1s and $\mathrm{O}$ 1s of the ELD coating, asdeposited and after being aged for $18 \mathrm{~h}$. Both spectra have appreciable changes. For further analysis, the $\mathrm{C} 1 \mathrm{~s}$ spectrum has been split into a few constituent components and investigated 
using the methodology proposed by Skaltsas and Modabberasl et al. [29, 30]. The C 1s main peak has been resolved into four components, including $\mathrm{C}=\mathrm{C}, \mathrm{C}-\mathrm{O} / \mathrm{C}-\mathrm{O}-\mathrm{C}, \mathrm{C}-\mathrm{C} / \mathrm{C}-\mathrm{H}$, and $\mathrm{COOH} / \mathrm{C}=\mathrm{O} . \mathrm{C}=\mathrm{C}$ and $\mathrm{C}-\mathrm{C} / \mathrm{C}-\mathrm{H}$ are the major components which are non-polar. The fitting has been processed based on the constraint of the intensity ratio of all the involved components. The atomic percentages of the components are shown in Tab.2. $\mathrm{C}=\mathrm{C}$ and $\mathrm{C}-\mathrm{C} / \mathrm{C}-\mathrm{H}$ group increase from 84.8 at $\%$ to 90.6 at $\%$, while $\mathrm{C}-\mathrm{O} / \mathrm{C}-\mathrm{O}-\mathrm{C}$ and $\mathrm{COOH} / \mathrm{C}=\mathrm{O}$ reduce from $15.2 \%$ to $9.4 \%$. The $\mathrm{O} 1 \mathrm{~s}$ spectrum has also been split into three different components. Here, referring to the nomenclature from Wei and Khan [31, 32], C-OH and O-H-O are designated as a combination of non-lattice oxygen and O-Metal groups as lattice oxygen. The lattice oxygen reduces from $23.8 \%$ to $15.5 \%$, while the ratio of non-lattice oxygen increases from $76.2 \%$ to $84.5 \%$. The non-lattice oxygen on the surface could also be contributed from the surface adsorption of oxygen gaseous species, e.g. hydroxyls and carbonates $[33,34]$. These oxygen groups might react with the moisture on the metallic coatings, leading to the occurrence of water dissociation, affecting the bonding between water molecules, and inhibiting the formation of water clusters [35]. It is estimated that one oxygen atom may influence about 5 8 water molecules in its vicinity. This could explain why the increased oxygen groups lead to the hydrophilicity.

The atomic percentage of hydrocarbons and the lattice oxygen of the ELD coating are also given in Tab.2. Compared to the value before, it clearly evidences that there is an obvious decrease in $\mathrm{C} 1 \mathrm{~s}$ contents. After the plasma cleaning, the overall ratios of $\mathrm{C}=\mathrm{C}$ and $\mathrm{C}-\mathrm{C} / \mathrm{C}-\mathrm{H}$ decrease from $90.6 \%$ to $73.7 \%$, which implies that these groups are the main parts of adsorbed airborne hydrocarbon species. The increase of $\mathrm{COOH} / \mathrm{C}=\mathrm{O}$ and $\mathrm{C}-\mathrm{O} / \mathrm{C}-\mathrm{O}-\mathrm{C}$ indicates that the extent of hydroxylation of the surface increases. $\mathrm{COOH} / \mathrm{C}=\mathrm{O}$ groups may work as hydrophilic groups and result in the hydrophilicity. Once an $\mathrm{OH}$-rich surface forms, wettability transition of the surface could be induced via the H-bonds with $\mathrm{OH}$ groups and other hydrophilic groups [36, 37]. For $\mathrm{O}$ 1s spectrum, an obvious change also takes place after the plasma cleaning process. 
The lattice-oxygen rises from $13.3 \%$ to $34.5 \%$. As a contrast, the non-lattice oxygen reduces from $86.7 \%$ to $65.5 \%$. The increased surface oxygen may prompt the formation of hydrogen bonds with interfacial water and induce lowered wettability [32]. After being stored in air, with enough surface adsorption, the atomic percentage of hydrocarbon recovered to $89.8 \%$, while the non-polar groups, $\mathrm{C}-\mathrm{O} / \mathrm{C}-\mathrm{O}-\mathrm{C}$ and $\mathrm{COOH} / \mathrm{C}=\mathrm{O}$ decrease from $26.3 \%$ to $10.2 \%$, showing the re-adsorption of the hydrocarbon groups. Possible adsorption on the surface may include different types of hydrocarbons, such as methyl, alkenes, acyclic $\mathrm{C}=\mathrm{C}$, aldehyde and so on, which come from the atmosphere [38]. The coverage of hydrocarbons would reach a certain value to turn into the hydrophobic state on micro-structured metal surfaces, it will take some time to build up the adsorption ratio of hydrocarbons $(\mathrm{C}=\mathrm{C}$ and $\mathrm{C}-\mathrm{C} / \mathrm{C}-\mathrm{H})$ [14]. When the adsorbed hydrocarbon molecules contact water, a repulsive hydrophobic force would take into effect [39]. In addition, the ratio of lattice oxygen decreases to $25.1 \%$ and non-lattice oxygen increase to $74.9 \%$. These polar groups are desorbed from the ELD coating surface which reduces the surface energy again to a critical value when being stored in ambient air. The $\mathrm{C}-\mathrm{OH}$ and $\mathrm{O}-$ $\mathrm{H}-\mathrm{O}$ groups re-predominate the surface, and the hydrophobic surface is recovered. The reversible wettability transition clearly indicates the effects of hydrocarbons and lattice oxygen on the coating surface.

\subsection{Icing of water droplets on the coatings}

Fig.5 displays the icing behaviour of water droplets on ED and ELD coatings and 304 SS substrate as a reference. The pillars represent the ice formation time before and after plasma cleaning. The ice formation time is an important parameter for icephobicity evaluation because it reflects the nucleation and growth of ice on certain surfaces [40]. Longer icing time means longer ice formation delay and a better anti-icing performance. The water droplet on 304 SS 
cooled down rapidly and ice nucleation has been triggered quickly with a duration of $16.8 \pm 1.3 \mathrm{~s}$. For ED and ELD samples, the ice formation was significantly delayed with respect to 304 SS, and it took a prolonged period of time $(217.3 \pm 25.6 \mathrm{~s}$ for ED coating and $139.0 \pm 21.3 \mathrm{~s}$ for ELD coating, respectively) to form ice. The difference reveals that the hydrophobic state of the coatings plays an important role in the delay of ice formation compared to the bare substrates. There would be air pockets remaining on the coating surface, helping to form solid-liquid interface with reduced contact areas which could decrease the thermal exchange [41]. Smaller water-solid contact area also leads to lower liquid-solid nucleation rate under the icing condition. The air pockets could impede heat conduction and result in icing delay [42]. The adsorbed hydrocarbon groups may also form a thin low surface energy layer at the interface, providing an additional barrier for the water droplets, and making them difficult to penetrate into the surface pores and cavities. And a composite solid-air-liquid interface would be formed, in contrast with the homogeneous solid-liquid interface [43].

The icing delay effect of ED coating is better than that of ELD coating. The difference in icing duration may come from the difference of surface morphology and wettability. The hierarchical structures of ED coatings could supply larger specific area and the cavities of the hierarchical structure could create more opportunity to form air pockets at the interface and further lead to a smaller solid-liquid interface fraction. From Tab.3, the WCA of ED is $143.8 \pm 3.9^{\circ}$, and contact angle hysteresis $(\mathrm{CAH})$ is $5.5^{\circ}$; while the WCA of ELD is $105.1 \pm 3.5^{\circ}$, and $\mathrm{CAH}$ is $19.3^{\circ}$. The high WCA and low $\mathrm{CAH}$ reduce the ice-solid contact area and the energy of the adhesive bond at the interface [44]. These factors help ED coatings with better icing delay effect than ELD coatings.

After the plasma cleaning, the icing times of ED and ELD coatings greatly decrease to only $14.7 \pm 3.8 \mathrm{~s}$ and $13.6 \pm 0.8 \mathrm{~s}$, respectively. There are several possible reasons. Firstly, with the removal of surface adsorption, the trapped air pockets would no longer form immediately after 
the plasma cleaning, and the solid-liquid interface fraction would increase. Secondly, the WCA decreases sharply. The WCA of ED become $7.8^{\circ}$ while the value for ELD become $18.6^{\circ}$. The inserted images give the profiles of the water droplets on the coating surface. With same water droplet volume, the difference in WCA and CAH could lead to the change of water droplet base width difference and the actual solid-liquid contact area. In Tab.4, the WCA and base width of the water droplet on ED and ELD before and after plasma cleaning have been presented. The base width of ED before plasma cleaning is only $1.87 \mathrm{~mm}$ and then it increases sharply to 7.56 $\mathrm{mm}$ after plasma cleaning. In addition, for ELD sample, the base width increases from $3.19 \mathrm{~mm}$ to $6.68 \mathrm{~mm}$. The corresponding increase of solid-liquid contact area means more thermal exchange between the solid-liquid interfaces, as well as more solid-liquid nucleation sites. Thirdly, the plasma cleaning treatment removes the adsorbed hydrocarbons on the coating surface, which previously formed a thin low surface energy layer at the interface. Then the droplet would have more direct interaction with the solid surface. The introduction of hydrophilic groups on the coating surface after the plasma cleaning might also accelerate the icing formation.

The icing process on a certain surface could be considered as a phase transition. The whole process would certainly be affected by the WCA. The phase transition causes the decrease of Gibbs free energy. The water droplet needs to overcome the potential barrier to fulfill the phase transition (from liquid phase to solid state) [45]:

$$
\begin{gathered}
\Delta G c=\frac{4}{3} \pi r_{c}^{2} \sigma_{1 v} f(\theta) \\
\text { Where } f(\theta)=\frac{\left(2-3 \cos \theta+\cos ^{3} \theta\right)}{4} \leq 1
\end{gathered}
$$

$\Delta G c$ is the critical potential barrier $(\mathrm{J}) ; r_{c}$ is the critical radius $(\mathrm{m}) ; \sigma_{1 v}$ is the surface tension between air and the liquid phase $(\mathrm{N} / \mathrm{m})$; and $\theta$ is CA between water droplet and solid surface $\left(^{\circ}\right)$. 
The critical radius $r_{c}$ for a certain surface is a constant. While the surface tension $\sigma_{1 v}$ has some influencing factors, including the molecular forces, temperature, pressure and so on. In this system, the molecular forces, temperature, pressure remains unchanged.

The WCAs are different on the ED and ELD coating, and different $\theta$ could lead to variation in $\Delta G c$. High WCA produces high $\Delta G c$, which makes the water droplet phase transition more difficult. After the plasma cleaning, the hydrophilic groups are introduced onto the surface, these polar groups would act as the surfactant, which help to decrease the surface tension. More hydrophilic groups mean higher surfactivity and lower surface tension value. So after the plasma cleaning, the potential barrier needed for icing process is also significantly reduced, and the ice formation becomes much quicker than before [46].

\subsection{Ice adhesion strength of the coatings}

Determination of ice adhesion on a surface is a common approach for icephobicity assessment. Lower ice adhesion strength means easier detachment of the ice from the surface which is desirable for de-icing. Fig.6 show the ice adhesion results of ED coatings, ELD coatings and 304 SS substrate, respectively. The pillars represent the shear strengths before and after plasma cleaning. The shear strength of $304 \mathrm{SS}$ substrate is $94.3 \pm 4.3 \mathrm{KPa}$, while the shear strength of ED is $65.6 \pm 4.0 \mathrm{KPa}$, and the shear strength of ELD is $64.1 \pm 15.2 \mathrm{KPa}$. This means that the coatings could reduce the ice adhesion strength, with a decrease of around 35\%. From Tab.3, the ED coating possesses higher WCA and lower CAH than ELD coating. Lower CAH could reduce the surface contact area and the energy of the adhesive bond, which may also attribute to the formation of air pockets and help to reduce the bonding of ice-solid interface [44]. But the surface morphology of ED coating is more hierarchical than that of ELD coating with a higher surface roughness. The maintained air pockets on the rougher structure tend to have a higher possibility of interface defects, crack nucleation and propagation [39]. After the plasma cleaning, the shear 
strengths of ED and ELD coatings increase to $160 \pm 11.3 \mathrm{KPa}$ and $141 \pm 8.9 \mathrm{KPa}$, respectively. The two coatings present a similar rising trend. The ice adhesion strength is largely related to hydrogen bonding, van der Waals forces and electrostatic interaction [47]. Among them, the electrostatic interaction could be the dominant factor [48]. Icephobic coating with low surface energy would reduce the molecular interaction between water and the coating surface. The changes of surface energy of ED and ELD coatings indicate the same trend as ice adhesion strength: for ED coating, from $28.3 \mathrm{~mJ} / \mathrm{m}^{2}$ to $72.70 \mathrm{~mJ} / \mathrm{m}^{2}$; while for ELD coating, from 35.54 $\mathrm{mJ} / \mathrm{m}^{2}$ to $69.23 \mathrm{~mJ} / \mathrm{m}^{2}$. The reason for the increase of surface energy could be the removal of surface hydrocarbons and no longer formed air pockets. The surfaces change into the hydrophilic state after plasma cleaning, and the water and substrate would have more direct contact. The low WCA makes the water droplet easily penetrate into the cavities at the interface and form the ice inside which can be called interlocked ice. Therefore, the ice adhesion becomes much stronger than that in the hydrophobic state. The formation of interlocked ice on the coating surface would increase the ice adhesion inevitably, which is further evidenced in Section 3.7. Therefore, the changes of surface energy could also confirm the effect of gaseous adsorption on the surface icephobicity of the coatings.

\subsection{Water condensation and icing study}

ESEM is used to study the water condensation, ice nucleation and formation on the ELD and ED coatings. Fig.7 shows the water droplet condensation on the ELD coating that stored in ambient air for $18 \mathrm{~h}$. Fig. 7(a) is the initial state of the ELD coating, while in Fig. 7(b), with the humidity and pressure control, the water condenses and distributes randomly on the surface, and the droplet size varies accross the observed surface. The water condensation starts along with the rough asperities of the coatings, which may act as the nucleation seeds for the water condensation [9]. From the area circled in red, which is enlarged in Fig. 7(c) - (f), water droplets form and keep growing. At the beginning, only small water droplets appear. With increasing 
condensation by controlling humidity, pressure and temperature, water droplets gradually increase and then merge together to form a big area of water. These SEM images clearly indicate the growth and merging of the water droplets. As the temperature decreases, micro-droplets $(\leq 1$ $\mathrm{mm}$ ) are randomly scattered on the coating surface, and the hydrophobic characteristics of the ELD coating could be clearly reflected. Once a dynamic equilibrium has been obtained between the micro-droplet condensation and evaporation, the static WCA could be determined, which is consistent with the measured static WCA [47].

Fig.8 shows the water condensation of ELD coating immediately after plasma cleaning, which means the surface is hydrophilic with WCA lower than $20^{\circ}$. The major difference lies that the condensed water does not appear in the form of hydrophobic micro-droplets. The water droplets condense and merge into big area of water, showing hydrophilic characteristic. With the continuous condensation, water would finally spread to the whole observation area.

Fig. 9 demonstrates the in-situ icing process of ELD coating after plasma cleaning. Further to the water condensation, the temperature has been adjusted to below $0{ }^{\circ} \mathrm{C}$, the surface rough structures of the coating provide the ice nucleation sites, where ice nucleation and growth occur [48]. In Fig 9 (a), there is a large piece of ice block formed on the coating. There are two dark areas (marked in red) in the images. The dark area is water that remains in these lower parts surrounded by some nodular structures. Indicated by the enlarged images Fig.9 (b)-(d) and (e)$(\mathrm{g})$, these areas would induce the formation of ice earlier than other places. The water remaining areas seem to have preferences in icing, and the formed ice would also have strong links with the substrate, in which ice interlocking cold be found. This could explain the high ice adhesion strength in Fig. 6. With proper humidity and pressure, the ice would keep growing.

Fig. 10 displays the water droplet condensation on ED coating before plasma cleaning, with hierarchical structure and a higher WCA up to $140^{\circ}$. The micro droplets keep growing in 
size and the surface hydrophobicity could be reflected from the geometry of the micro droplets. When the droplet grows to a certain size, it would fall off and merges into the big water area. Because of the hierarchical structure, there are a lot of peaks and valleys, the gathered water normally stays in the lower area, while the higher position is less affected.

Fig. 11 (a) and (b) show water droplet condensation on ED coating after plasma cleaning with WCA around $10^{\circ}$. The condensed droplets gather at the lower area, since the WCA is low and air pockets no longer form, there is no hydrophobic characteristic of micro droplets. The hierarchical structure with peaks and valleys are inundated with water. Fig. 11 (c) shows the water condensation and icing on ED coating after plasma cleaning. The formation of ice blocks on the surface are clearly observed. From Fig. 11 (d), it seems that some ice forms in the microscopic pores and the preferred icing area is around the hierarchical structures[49]. The ice build-up between the hierarchical structures could generate mechanical interlocking. It is obvious that the value of ice adhesion strength would be much higher for coating with the interlocked ice blocks, as presented in Fig.6.

Herein, the schematic diagram in Fig. 12 indicates the effect and mechanism of surface adsorption on coating icephobicity. The upper images are the coatings in as prepared/plasma cleaned states. When limited hydrocarbon species are adsorbed on the coating surface, it shows hydrophilic state. The interaction of the water droplet on the coating surface is indicated in the upper-left image, showing typical hydrophilic character and the water droplet occupies the space between the rough asperities. The upper-right image is the ice accretion on the coating surface, and the formed ice fills in the space between the hierarchical structures. The formed ice has close interaction with the rough asperities, which could lead to mechanical interlocking and increase the ice adhesion strength. The images below are the water condensation and ice formation on coating surface after being stored in ambient air for enough time. After being stored in air, a large amount of hydrocarbon species is adsorbed onto the coating surface, leading to a signficant 
decrease in surface energy. Due to the contribution of the adsorbed hydrocarbon species and the hierarchical structures, the formation of air pockets is demonstrated. Also benefit from the lowered surface energy, the formed ice would have much less interlocking effect and bonding on the coating surface, indicating a better surface icephobicity.

\section{Conclusions}

The effect of surface gaseous adsorption on icing behaviour of $\mathrm{Ni}-\mathrm{Cu}-\mathrm{P}$ ternary coatings was studied systematically. The results showed that the icing time of water droplets on the Ni$\mathrm{Cu}-\mathrm{P}$ coatings increased significantly, and the ice adhesion strength decreased sharply with the spontaneous surface gaseous adsorption in air. XPS analysis indicated that the adsorbed hydrocarbons played an important role in the change of icing behaviour of the coatings. With the removal of surface adsorption by plasma cleaning, the surface icephobicity of the Ni-Cu-P coating deteriorated. ESEM observation confirmed the role of air pockets and the presence of the interlocked ice. The adsorbed hydrocarbons would help to form a good amount of air pockets at the water-solid interface, which could decrease the interfacial contact effectively between the water droplets and coatings and further hinder the formation of interlocked ice. The changes of surface energy could also confirm the effect of gaseous adsorption on coating icephobicity. Due to the universal surface adsorption phenomenon in air, the mechanism disclosed in this study is likely to be applicable to other metallic coatings and surfaces.

Acknowledgments: The work is supported by a joint Ph.D. studentship between China Scholarship Council (CSC) and The University of Nottingham. This work was supported in part by the European Commissions' Horizon 2020 Framework Program (H2020/2014-2020) through CTFF Project under Grant 777717. The access of characterisation facilities was also acknowledged at Nanoscale and Microscale Research Centre of the University of Nottingham, 
supported in part by the Engineering and Physical Sciences Research Council [grant number EP/L022494/1], as well as University of Nottingham Propulsion Futures Beacon for funding under Grant PF020. Dr. Barbara Turnbull at University of Nottingham kindly helped for ice adhesion strength test.

\section{References}

[1] M.J. Kreder, J. Alvarenga, P. Kim, J. Aizenberg, Design of anti-icing surfaces: smooth, textured or slippery?, Nature Reviews Materials, 1 (2016) 15003.

[2] L.B. Boinovich, A.M. Emelyanenko, V.K. Ivanov, A.S. Pashinin, Durable icephobic coating for stainless steel, ACS applied materials \& interfaces, 5 (2013) 2549-2554.

[3] R. Ramachandran, K. Sobolev, M. Nosonovsky, Dynamics of droplet impact on hydrophobic/icephobic concrete with the potential for superhydrophobicity, Langmuir, 31 (2015) 14371444.

[4] P. Guo, Y. Zheng, M. Wen, C. Song, Y. Lin, L. Jiang, Icephobic/anti - icing properties of micro/nanostructured surfaces, Advanced Materials, 24 (2012) 2642-2648.

[5] J. Liu, J. Wang, L. Mazzola, H. Memon, T. Barman, B. Turnbull, G. Mingione, K.-S. Choi, X. Hou, Development and evaluation of poly (dimethylsiloxane) based composite coatings for icephobic applications, Surface and Coatings Technology, 349 (2018) 980-985.

[6] S. Zheng, C. Li, Q. Fu, T. Xiang, W. Hu, J. Wang, S. Ding, P. Liu, Z. Chen, Fabrication of a micronanostructured superhydrophobic aluminum surface with excellent corrosion resistance and anti-icing performance, RSC Advances, 6 (2016) 79389-79400.

[7] M. Ruan, W. Li, B. Wang, B. Deng, F. Ma, Z. Yu, Preparation and anti-icing behavior of superhydrophobic surfaces on aluminum alloy substrates, Langmuir, 29 (2013) 8482-8491.

[8] X. Wu, V.V. Silberschmidt, Z.-T. Hu, Z. Chen, When superhydrophobic coatings are icephobic: Role of surface topology, Surface and Coatings Technology, 358 (2019) 207-214.

[9] P. Kim, T.-S. Wong, J. Alvarenga, M.J. Kreder, W.E. Adorno-Martinez, J. Aizenberg, Liquid-infused nanostructured surfaces with extreme anti-ice and anti-frost performance, ACS nano, 6 (2012) 6569-6577.

[10] A.J. Meuler, J.D. Smith, K.K. Varanasi, J.M. Mabry, G.H. McKinley, R.E. Cohen, Relationships between water wettability and ice adhesion, ACS applied materials \& interfaces, 2 (2010) 3100-3110.

[11] S. Farhadi, M. Farzaneh, S. Kulinich, Anti-icing performance of superhydrophobic surfaces, Applied Surface Science, 257 (2011) 6264-6269.

[12] H. Sojoudi, M. Wang, N. Boscher, G. McKinley, K. Gleason, Durable and scalable icephobic surfaces: similarities and distinctions from superhydrophobic surfaces, Soft matter, 12 (2016) 1938-1963.

[13] R. Menini, M. Farzaneh, Advanced icephobic coatings, Journal of adhesion science and technology, 25 (2011) 971-992.

[14] P. Liu, L. Cao, W. Zhao, Y. Xia, W. Huang, Z. Li, Insights into the superhydrophobicity of metallic surfaces prepared by electrodeposition involving spontaneous adsorption of airborne hydrocarbons, Applied Surface Science, 324 (2015) 576-583.

[15] C. Zhou, H. Li, J. Lin, K. Hou, Z. Yang, P. Pi, S. Xu, X. Wen, J. Cheng, Matchstick-Like Cu2S @ $\mathrm{Cu}_{\mathrm{x}} \mathrm{O}$ Nanowire Film: Transition of Superhydrophilicity to Superhydrophobicity, The Journal of Physical Chemistry C, 121 (2017) 19716-19726. 
[16] X. Feng, L. Feng, M. Jin, J. Zhai, L. Jiang, D. Zhu, Reversible super-hydrophobicity to superhydrophilicity transition of aligned $\mathrm{ZnO}$ nanorod films, Journal of the American Chemical Society, 126 (2004) 62-63.

[17] A. Chaudhary, H.C. Barshilia, Nanometric multiscale rough $\mathrm{CuO} / \mathrm{Cu}(\mathrm{OH})_{2}$ superhydrophobic surfaces prepared by a facile one-step solution-immersion process: transition to superhydrophilicity with oxygen plasma treatment, The Journal of Physical Chemistry C, 115 (2011) 18213-18220.

[18] J. Wang, J. Liu, N. Neate, M. Bai, F. Xu, T. Hussain, C. Scotchford, X. Hou, Investigation on timedependent wetting behavior of Ni-Cu-P ternary coating, Journal of Alloys and Compounds, 765 (2018) 221-228.

[19] C. Laforte, A. Beisswenger, Icephobic material centrifuge adhesion test, Proceedings of the 11th International Workshop on Atmospheric Icing of Structures, IWAIS, Montreal, QC, Canada, 2005, pp. $12-16$.

[20] A. Rudawska, E. Jacniacka, Analysis for determining surface free energy uncertainty by the OwenWendt method, International Journal of Adhesion and Adhesives, 29 (2009) 451-457.

[21] Q. Mai, R. Daniels, H. Harpalani, Structural changes induced by heating in electroless nickelphosphorus alloys, Thin Solid Films, 166 (1988) 235-247.

[22] J. Balaraju, K. Rajam, Electroless deposition of Ni-Cu-P, Ni-W-P and Ni-W-Cu-P alloys, Surface and Coatings Technology, 195 (2005) 154-161.

[23] Y. Song, D. Liu, X. Song, S. Hu, J. Cao, In - situ synthesis of TiC nanoparticles during joining of SiC ceramic and GH 99 superalloy, Journal of the American Ceramic Society, 102 (2019) 6529-6541.

[24] M.F. Ordoñez, C.L. Amorim, I. Krindges, C. Aguzzoli, I.J. Baumvol, C.A. Figueroa, A. Sinatora, R.M. Souza, M.C.M. Farias, Microstructure and micro-abrasive wear of sintered yttria-containing 316L stainless steel treated by plasma nitriding, Surface and Coatings Technology, 374 (2019) 700-712.

[25] Z. Cheng, H. Lai, Y. Du, K. Fu, R. Hou, N. Zhang, K. Sun, Underwater superoleophilic to superoleophobic wetting control on the nanostructured copper substrates, ACS applied materials \& interfaces, 5 (2013) 11363-11370.

[26] C.-J. Yang, F.-H. Lu, Shape and size control of $\mathrm{Cu}$ nanoparticles by tailoring the surface morphologies of Tin-coated electrodes for biosensing applications, Langmuir, 29 (2013) 16025-16033.

[27] B. Willems, A.-L. Hamon, D. Schryvers, A.C. Robins, J.M. Matesa, P.E. Fischione, Plasma cleaning of carbonaceous samples using a shield, Microscopy and Microanalysis, 9 (2003) 164-165.

[28] D.J. Preston, N. Miljkovic, J. Sack, R. Enright, J. Queeney, E.N. Wang, Effect of hydrocarbon adsorption on the wettability of rare earth oxide ceramics, Applied Physics Letters, 105 (2014) 011601.

[29] T. Skaltsas, X. Ke, C. Bittencourt, N. Tagmatarchis, Ultrasonication Induces Oxygenated Species and Defects onto Exfoliated Graphene, The Journal of Physical Chemistry C, 117 (2013) 23272-23278.

[30] A. Modabberasl, P. Kameli, M. Ranjbar, H. Salamati, R. Ashiri, Fabrication of DLC thin films with improved diamond-like carbon character by the application of external magnetic field, Carbon, 94 (2015) 485-493.

[31] W. Wei, X. Cui, W. Chen, D.G. Ivey, Phase-controlled synthesis of $\mathrm{MnO}_{2}$ nanocrystals by anodic electrodeposition: implications for high-rate capability electrochemical supercapacitors, The Journal of Physical Chemistry C, 112 (2008) 15075-15083.

[32] S. Khan, G. Azimi, B. Yildiz, K.K. Varanasi, Role of surface oxygen-to-metal ratio on the wettability of rare-earth oxides, Applied Physics Letters, 106 (2015) 061601.

[33] L. Martinez, E.d. Roman, J. De Segovia, S. Poupard, J. Creus, F. Pedraza, Surface study of cerium oxide based coatings obtained by cathodic electrodeposition on zinc, Applied Surface Science, 257 (2011) 6202-6207. 
[34] J. Fan, X. Wu, L. Yang, D. Weng, The SMSI between supported platinum and $\mathrm{CeO}_{2}-\mathrm{ZrO}_{2}-\mathrm{La}_{2} \mathrm{O}_{3}$ mixed oxides in oxidative atmosphere, Catalysis Today, 126 (2007) 303-312.

[35] D.L. Doering, T.E. Madey, The adsorption of water on clean and oxygen-dosed Ru (011), Surface Science, 123 (1982) 305-337.

[36] M.A. Henderson, The interaction of water with solid surfaces: fundamental aspects revisited, Surface Science Reports, 46 (2002) 1-308.

[37] H.A. Al-Abadleh, V.H. Grassian, Oxide surfaces as environmental interfaces, Surface Science Reports, 52 (2003) 63-161.

[38] C.J. Illing, C. Hallmann, K.E. Miller, R.E. Summons, H. Strauss, Airborne hydrocarbon contamination from laboratory atmospheres, Organic geochemistry, 76 (2014) 26-38.

[39] V. Hejazi, K. Sobolev, M. Nosonovsky, From superhydrophobicity to icephobicity: forces and interaction analysis, Scientific reports, 3 (2013) 2194.

[40] Y. Shen, J. Tao, H. Tao, S. Chen, L. Pan, T. Wang, Anti-icing potential of superhydrophobic Ti6Al4V surfaces: ice nucleation and growth, Langmuir, 31 (2015) 10799-10806.

[41] B. Bhushan, Y.C. Jung, Wetting study of patterned surfaces for superhydrophobicity, Ultramicroscopy, 107 (2007) 1033-1041.

[42] L. Jiang, Y. Zhao, J. Zhai, A lotus - leaf - like superhydrophobic surface: a porous microsphere/nanofiber composite film prepared by electrohydrodynamics, Angewandte Chemie, 116 (2004) 4438-4441.

[43] G. Wang, Y. Shen, J. Tao, X. Luo, M. Jin, Y. Xie, Z. Li, S. Guo, Facilely constructing micronanostructure superhydrophobic aluminum surface with robust ice-phobicity and corrosion resistance, Surface and Coatings Technology, 329 (2017) 224-231.

[44] Z.A. Janjua, B. Turnbull, K.-L. Choy, C. Pandis, J. Liu, X. Hou, K.-S. Choi, Performance and durability tests of smart icephobic coatings to reduce ice adhesion, Applied Surface Science, 407 (2017) $555-564$.

[45] H. Wang, G. He, Q. Tian, Effects of nano-fluorocarbon coating on icing, Applied surface science, 258 (2012) 7219-7224.

[46] S.F. Burlatsky, V.V. Atrazhev, D.V. Dmitriev, V.I. Sultanov, E.N. Timokhina, E.A. Ugolkova, S. Tulyani, A. Vincitore, Surface tension model for surfactant solutions at the critical micelle concentration, Journal of colloid and interface science, 393 (2013) 151-160.

[47] Y. Jung, B. Bhushan, Wetting behaviour during evaporation and condensation of water microdroplets on superhydrophobic patterned surfaces, Journal of microscopy, 229 (2008) 127-140.

[48] S. Jung, M.K. Tiwari, N.V. Doan, D. Poulikakos, Mechanism of supercooled droplet freezing on surfaces, Nature communications, 3 (2012) 615.

[49] M. Landy, A. Freiberger, Studies of ice adhesion: I. Adhesion of ice to plastics, Journal of colloid and interface science, 25 (1967) 231-244. 


\section{List of Table captions}

Table 1 Surface energy of the electroless-deposited and electro-deposited Ni-Cu-P coatings

Table 2 Atomic percent change of hydrocarbon groups and lattice oxygen groups versus different treatments of electroless-deposited and electro-deposited $\mathrm{Ni}-\mathrm{Cu}-\mathrm{P}$ coating

Table 3 Wettability and surface roughness results of electroless-deposited and electro-deposited $\mathrm{Ni}-\mathrm{Cu}-\mathrm{P}$ coating

Table 4 The WCAs and water droplet base width versus different treatments of electrolessdeposited and electro-deposited $\mathrm{Ni}-\mathrm{Cu}-\mathrm{P}$ coating

Tab.1

\begin{tabular}{|c|c|c|}
\hline & \multicolumn{2}{|c|}{ Surface energy $\left(\mathrm{mJ} / \mathrm{m}^{2}\right)$} \\
\hline Samples & Aged in ambient air & After plasma cleaning \\
\hline ED coating & 28.30 & 72.70 \\
\hline ELD coating & 35.54 & 69.23 \\
\hline
\end{tabular}

Tab.2

\begin{tabular}{|c|c|c|c|}
\hline \multirow{4}{*}{ ELD coating } & Detailed Condition & Hydrocarbon in all (\%) & Lattice Oxygen (\%) \\
& As-deposited & 84.8 & 23.8 \\
\cline { 2 - 4 } & After 18 hours & 90.6 & 15.5 \\
\cline { 2 - 4 } & $\begin{array}{c}\text { Just after Plasma cleaning } \\
\text { ED Coating }\end{array}$ & 73.7 & 34.5 \\
\cline { 2 - 4 } & $\begin{array}{c}\text { As hours after Plasma } \\
\text { cleaning }\end{array}$ & 89.8 & 25.1 \\
\cline { 2 - 4 } & After 10 days & 78.7 & 27.9 \\
\cline { 2 - 4 } & $\begin{array}{c}\text { Before Plasma cleaning } \\
\text { (after 30 days) }\end{array}$ & 86.5 & 14.1 \\
\cline { 2 - 4 } & \begin{tabular}{c} 
Just After Plasma Cleaning \\
\cline { 2 - 4 }
\end{tabular} & 62.3 & 47.8 \\
\hline
\end{tabular}


Tab.3

\begin{tabular}{|c|c|c|c|c|c|}
\hline Coating & $\begin{array}{c}\text { Stabilised } \\
\mathrm{WCAs}\left({ }^{\circ}\right)\end{array}$ & $\begin{array}{c}\text { Advancing } \\
\mathrm{WCAs}\left({ }^{\circ}\right)\end{array}$ & $\begin{array}{c}\text { Receding } \\
\mathrm{WCAs}\left(^{\circ}\right)\end{array}$ & $\mathrm{CAH}\left(^{\circ}\right)$ & $\begin{array}{c}\text { Roughness, } \\
\mathrm{Ra}(\mu \mathrm{m})\end{array}$ \\
\hline ED coating & $143.8 \pm 3.9$ & 144.3 & 138.8 & 5.5 & $3.83 \pm 0.12$ \\
\hline ELD coating & $105.1 \pm 3.5$ & 104.9 & 85.6 & 19.3 & $0.50 \pm 0.02$ \\
\hline
\end{tabular}

Tab.4

\begin{tabular}{|c|c|c|c|}
\hline & Detailed Condition & WCAs $\left(^{\circ}\right)$ & Water droplet base width (mm) \\
\hline \multirow{2}{*}{ ED coating } & Aged in air & 143.8 & 1.87 \\
\cline { 2 - 4 } & Just after plasma cleaning & 7.8 & 7.56 \\
\hline \multirow{2}{*}{ ELD coating } & Aged in air & 105.1 & 3.19 \\
\cline { 2 - 4 } & Just after plasma cleaning & 18.6 & 6.68 \\
\hline
\end{tabular}




\section{Figures}

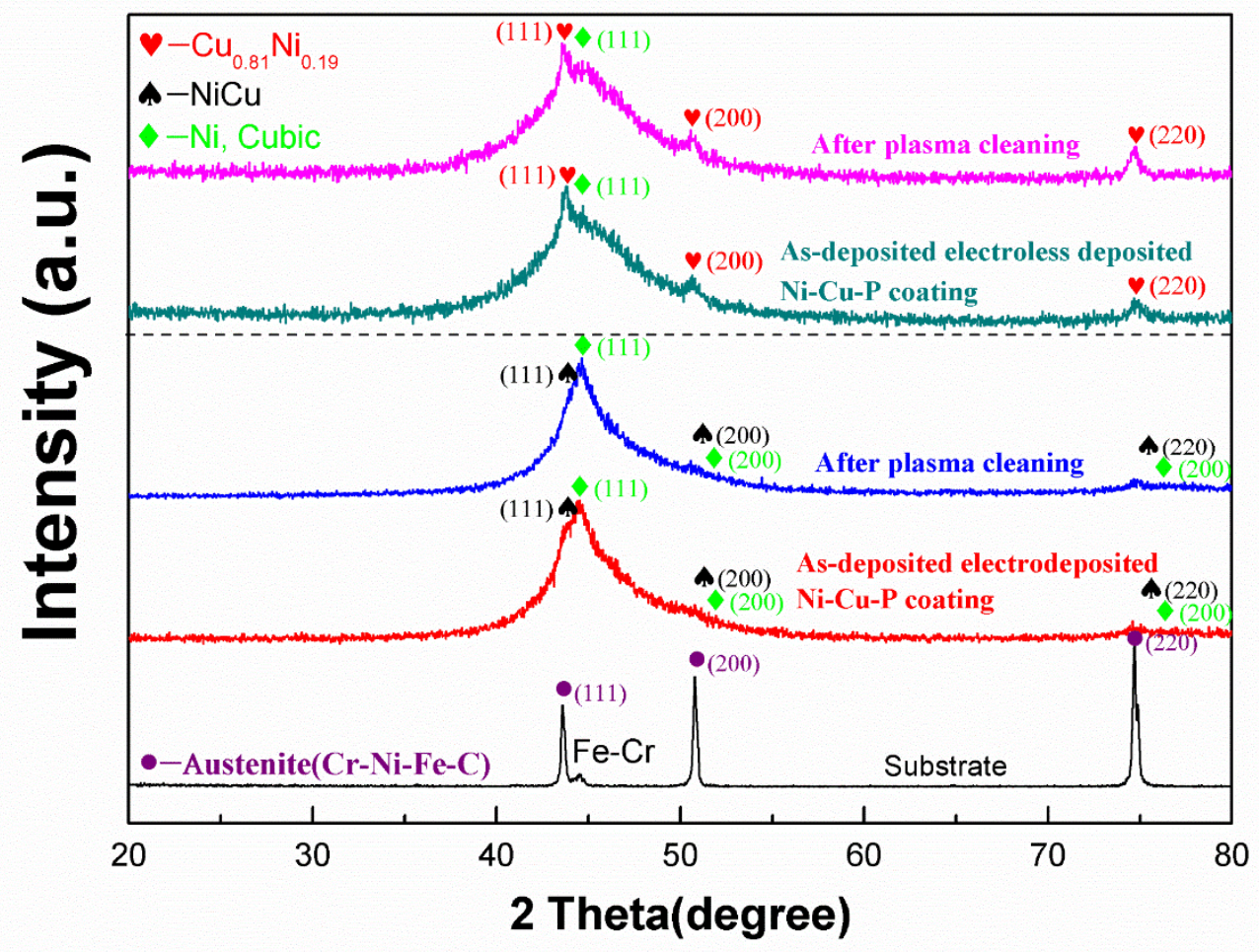

Figure 1 XRD patterns of 304 SS substrate, electrodeposited Ni-Cu-P coatings and electroless deposited Ni-Cu-P coatings 

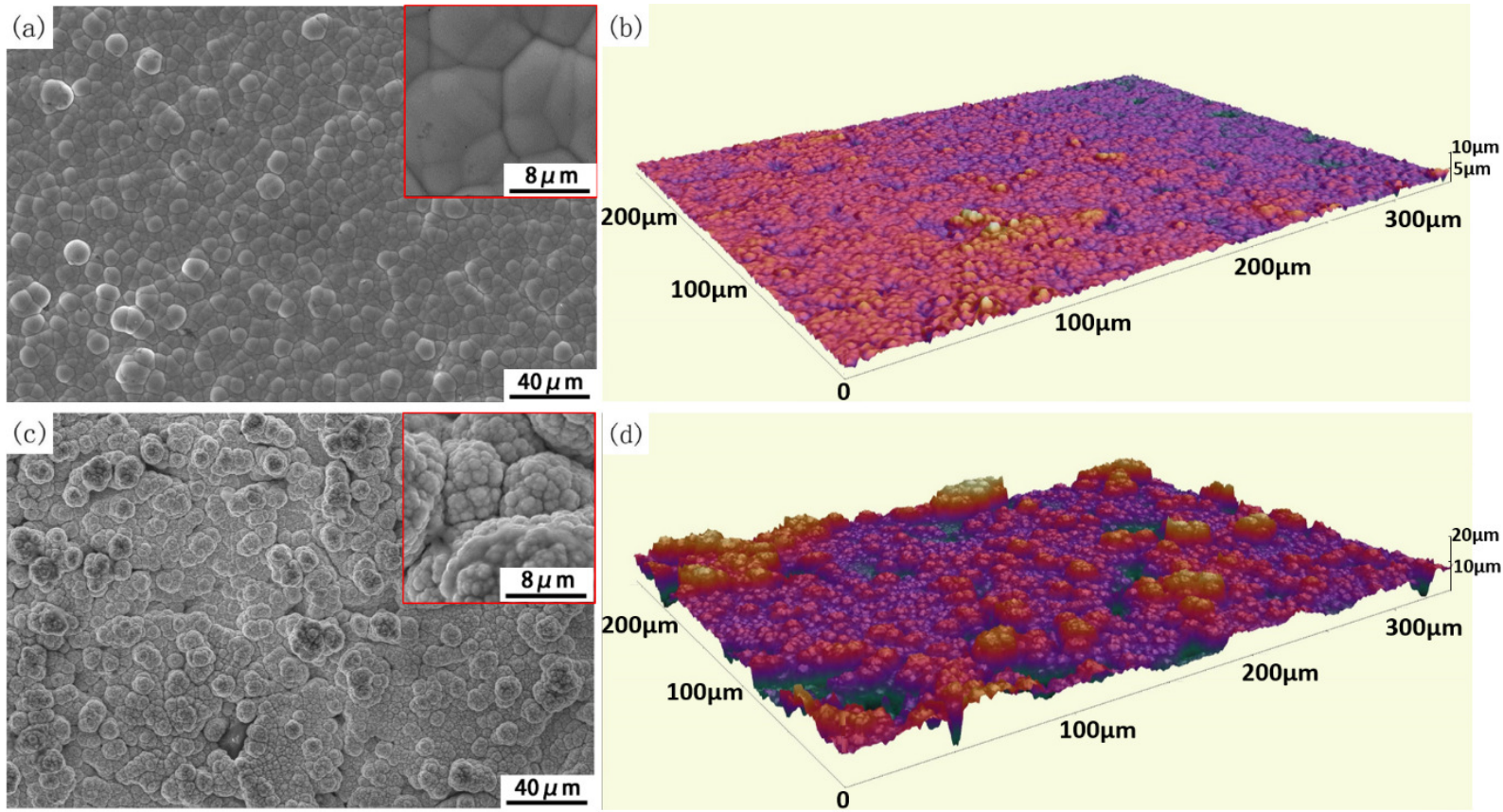

Figure 2 SEM images of (a) surface morphologies (b) 3D image of the electroless deposited Ni$\mathrm{Cu}-\mathrm{P}$ coating (c) surface morphologies (d) 3D image of the electro-deposited Ni-Cu-P coating 
(a)

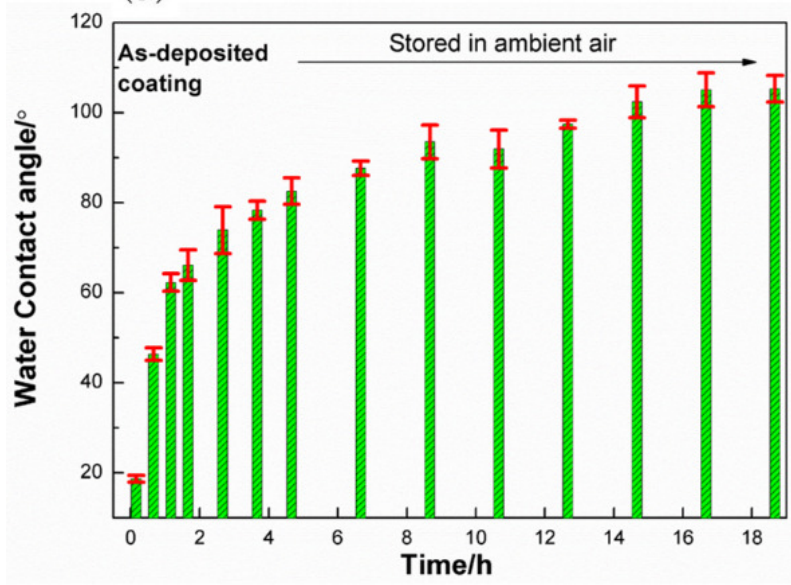

(b)

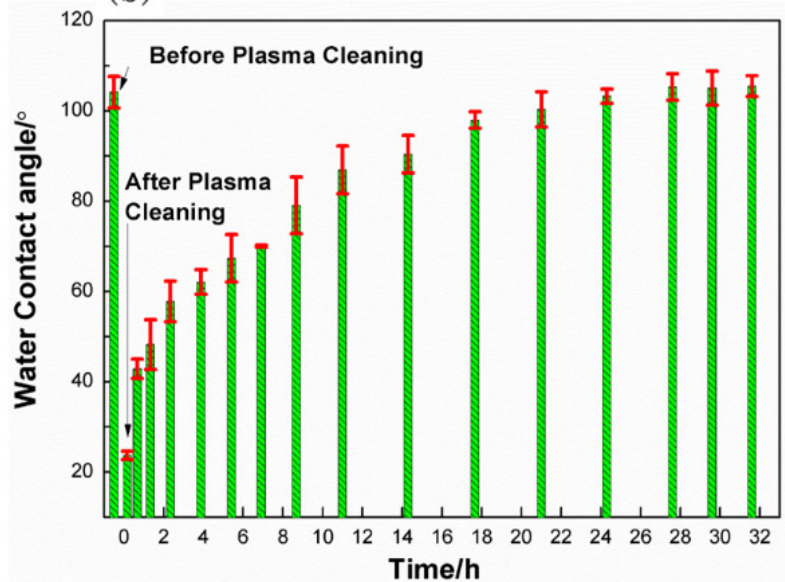

Figure 3 (a) WCA change within exposure time in ambient air of the electroless deposited Ni$\mathrm{Cu}-\mathrm{P}$ coating (b) WCA change of electroless deposited $\mathrm{Ni}-\mathrm{Cu}-\mathrm{P}$ coating before and after plasma cleaning 
(a)

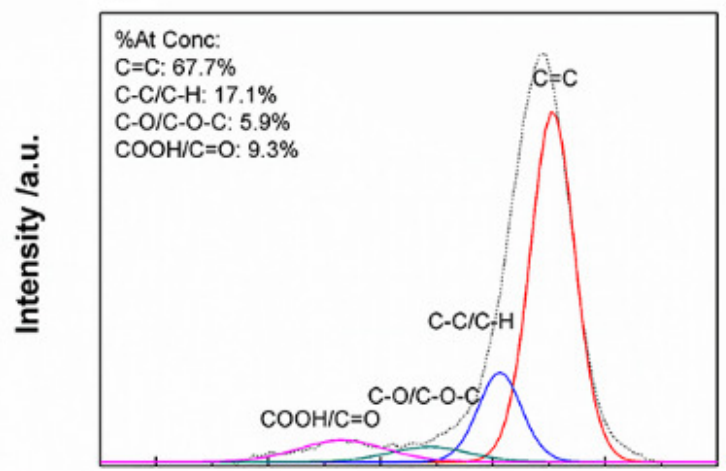

(b)

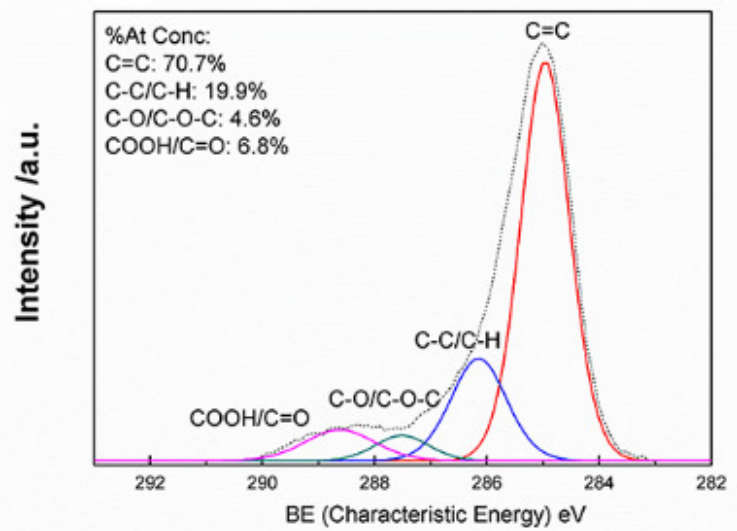

(c)

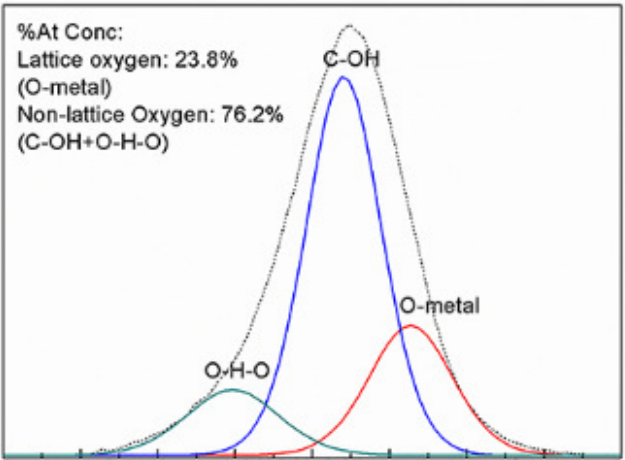

(d)

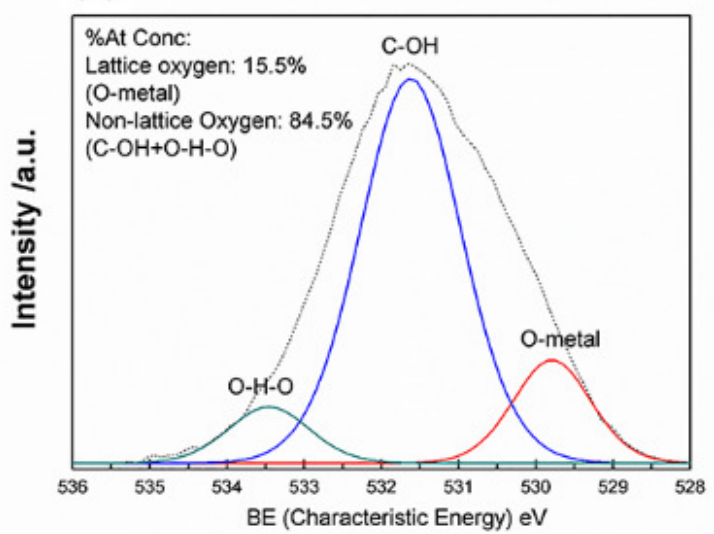

Figure 4 (a) and (b) C 1s XPS spectrum of the electroless deposited Ni-Cu-P coating (a) Asdeposited (b) After 18 hours (stored in ambient air); (c) and (d) O 1s XPS spectrum of the electroless deposited Ni-Cu-P coating (c) As-deposited (d) After 18 hours (stored in ambient air) 


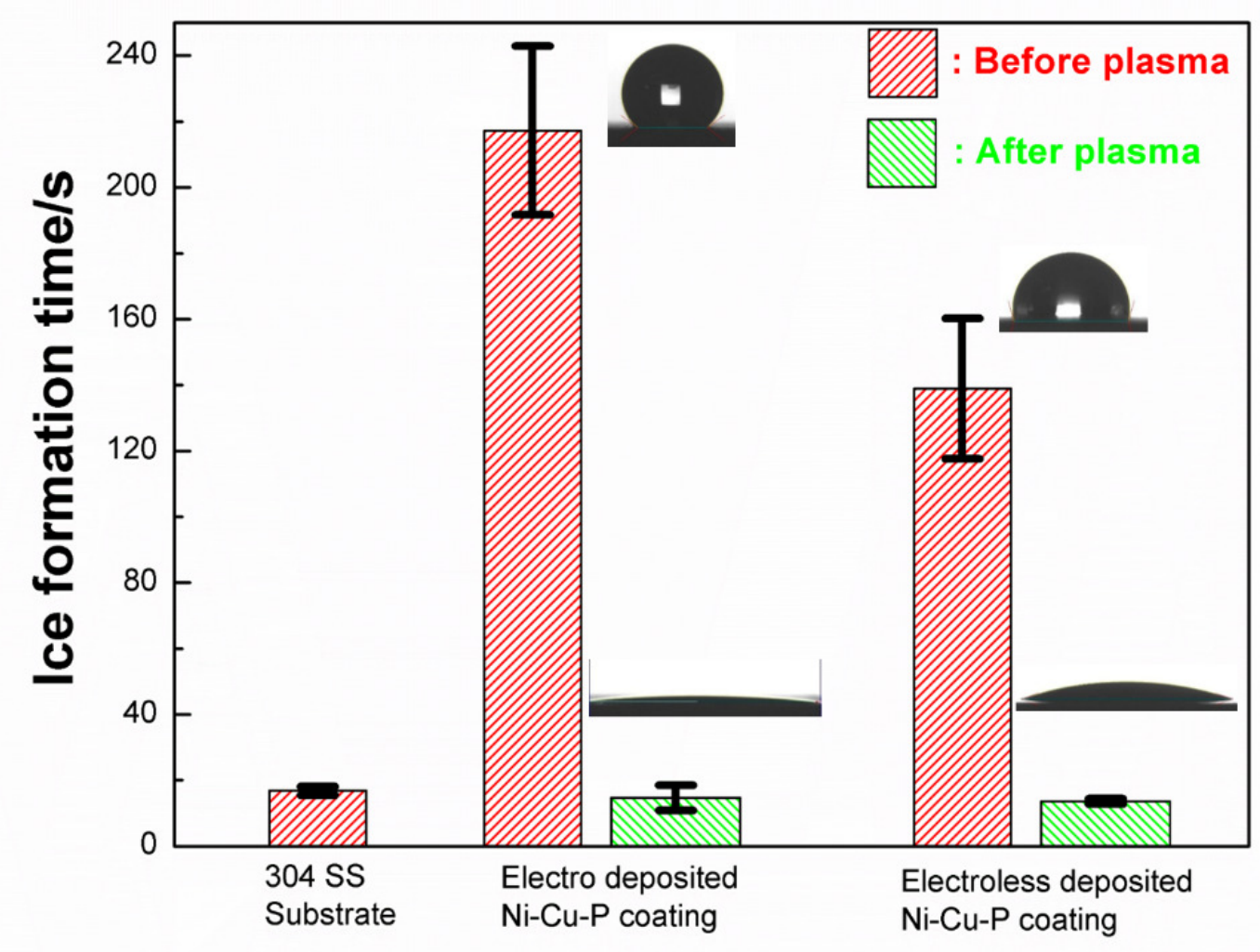

Figure 5 Icing-delay performance of 304 SS, electro-deposited, electroless-deposited Ni-Cu-P coating aged in ambient air and after plasma cleaning 


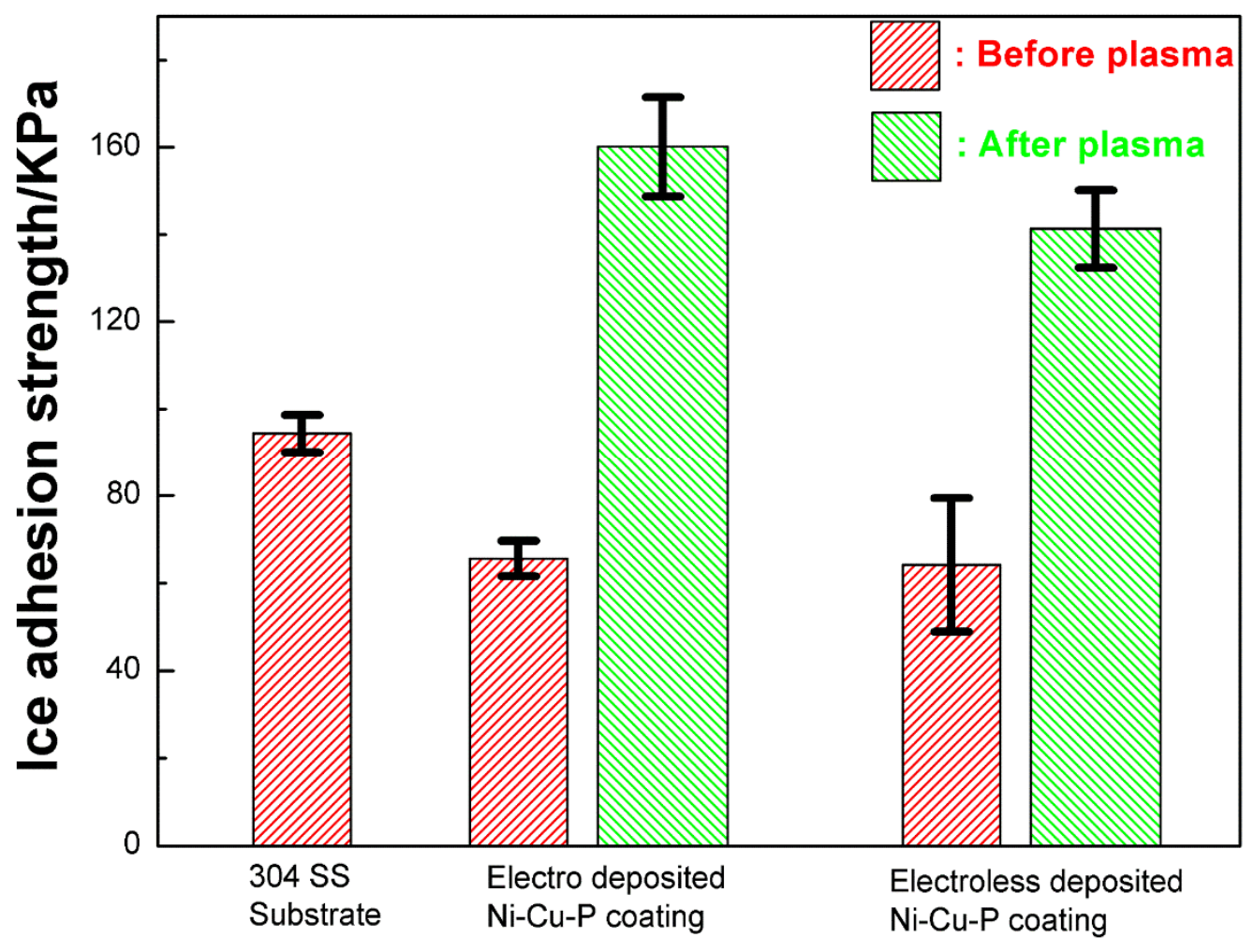

Figure 6 Ice adhesion results of 304 SS, electro-deposited, electroless-deposited Ni-Cu-P coating aged in ambient air and after plasma cleaning 

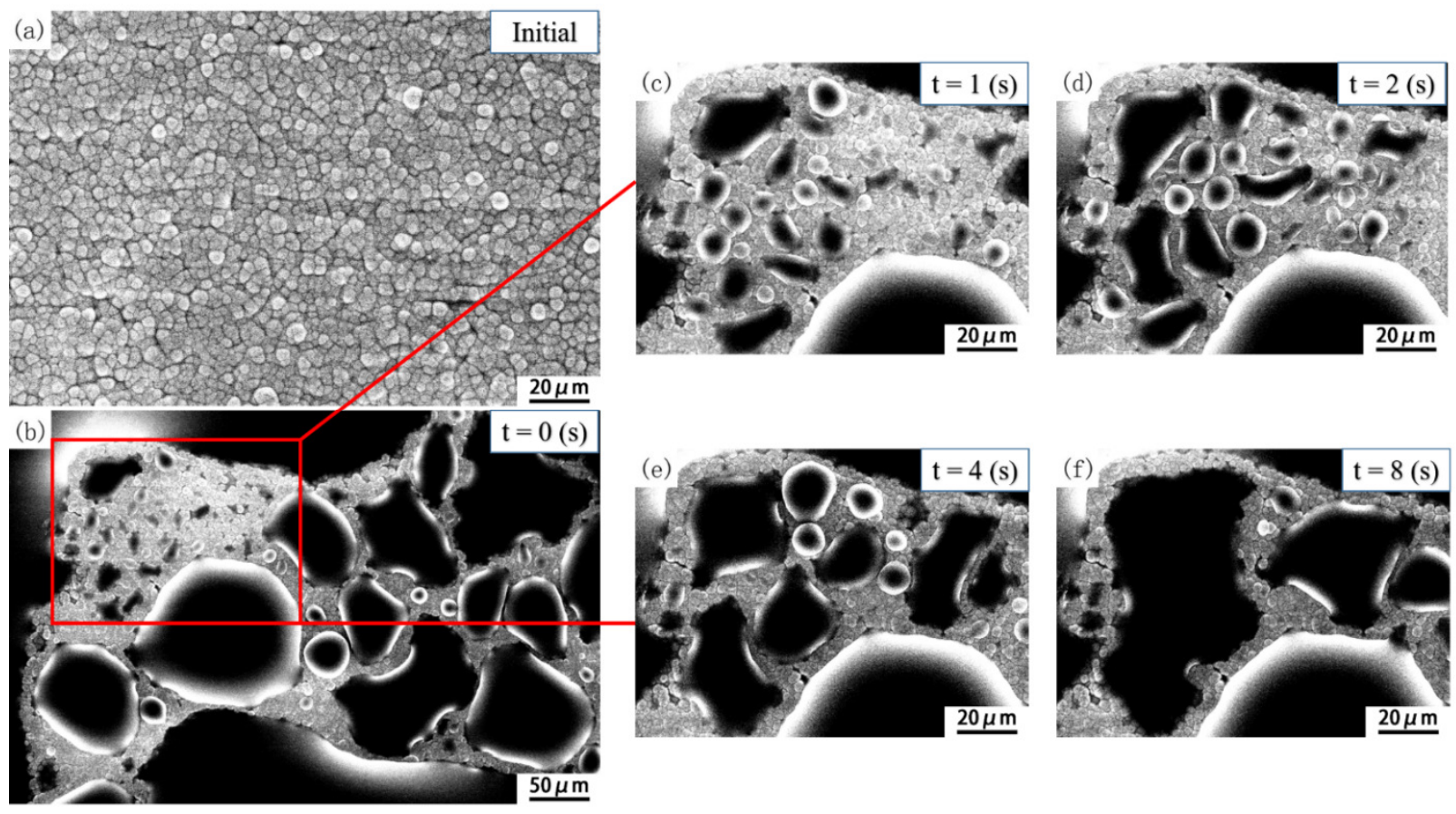

Figure 7 Water condensation and gathering process on electroless-deposited $\mathrm{Ni}-\mathrm{Cu}-\mathrm{P}$ coating aged in ambient air (Pressure: 5.4 torr; Temp: $3.0{ }^{\circ} \mathrm{C}$; humidity: $95.0 \%$ ) 


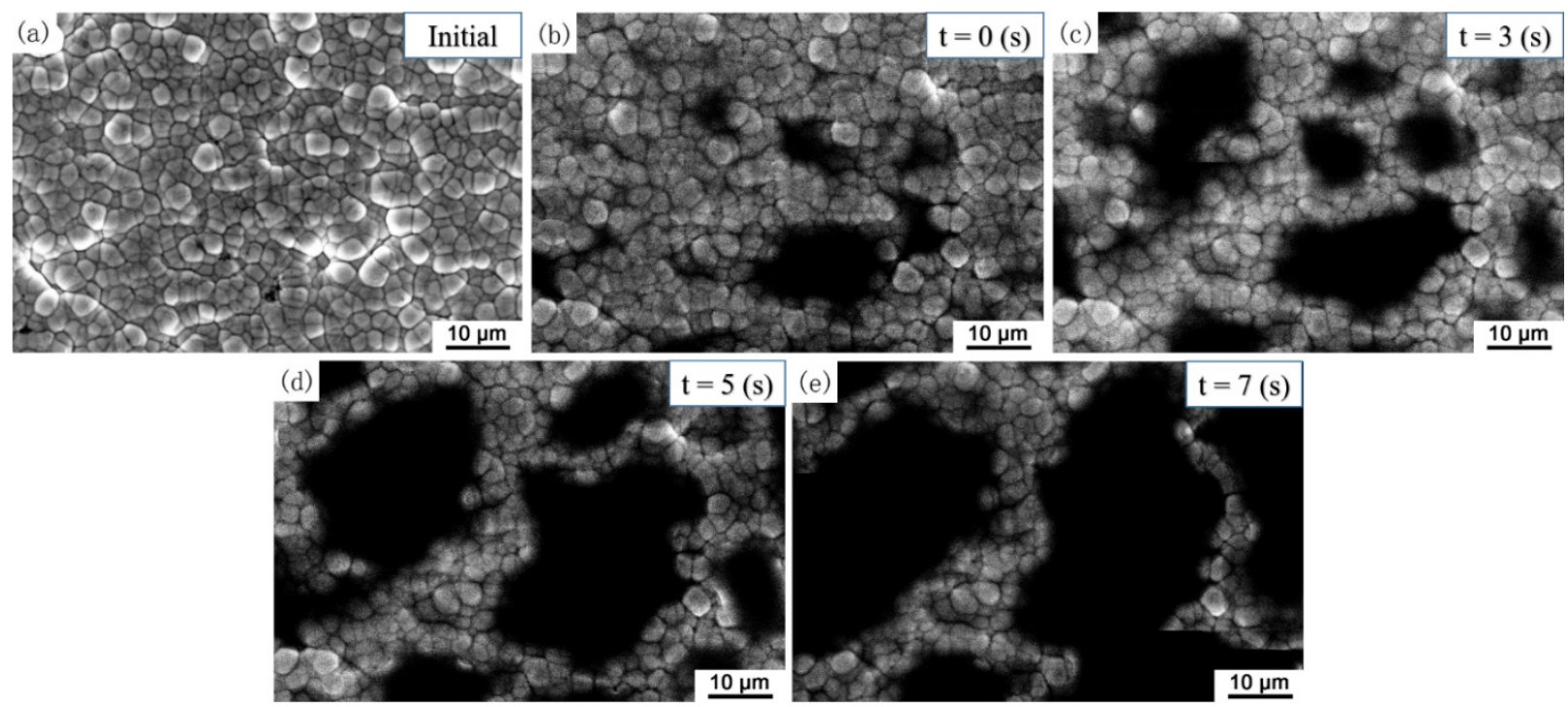

Figure 8 Water condensation and gathering process on electroless-deposited $\mathrm{Ni}-\mathrm{Cu}-\mathrm{P}$ coating after plasma cleaning (Pressure: 5.3 torr; Temp: $2.0{ }^{\circ} \mathrm{C}$; humidity: $100 \%$ ) 


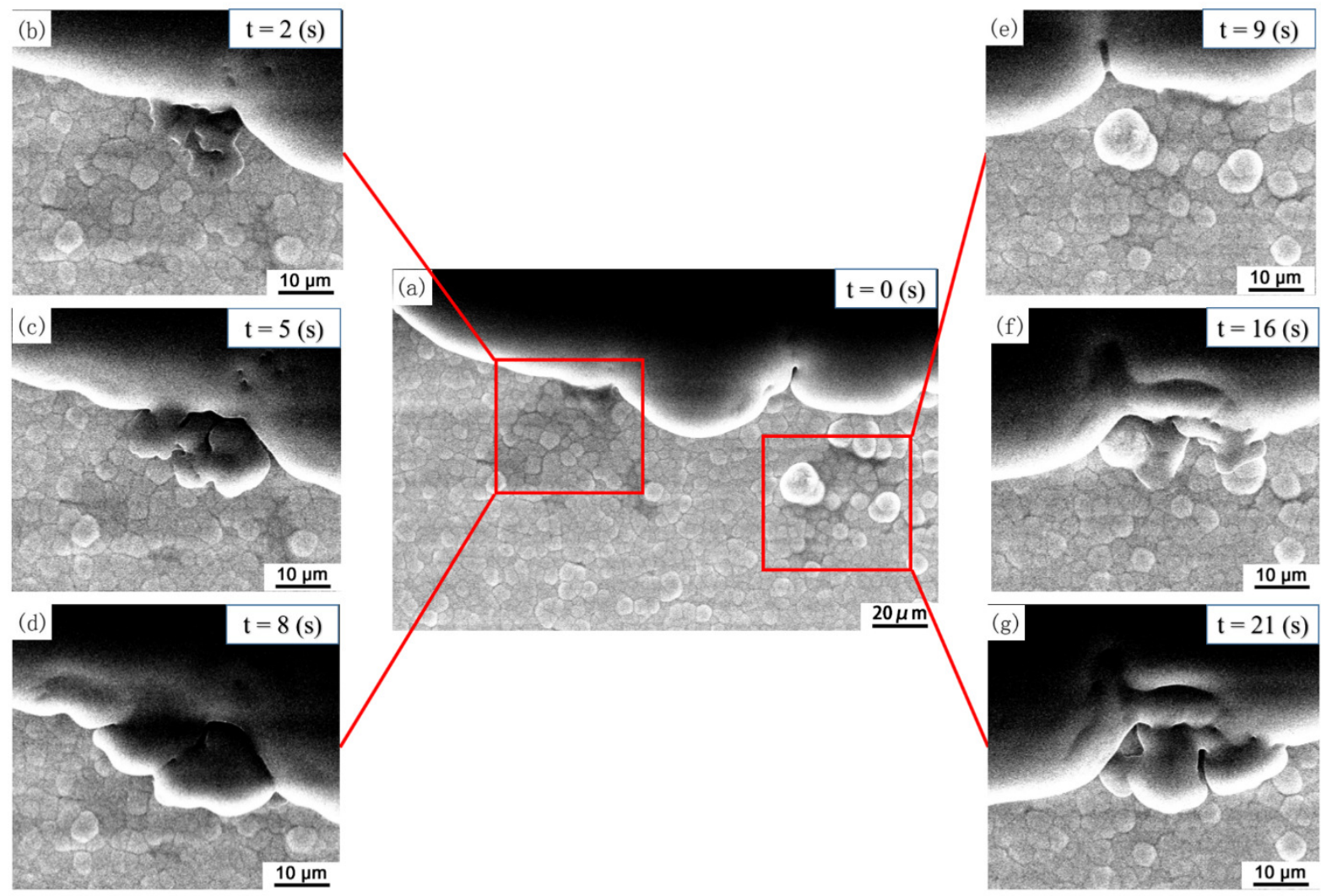

Figure 9 Ice formation process on electroless-deposited Ni-Cu-P coating after plasma cleaning (Pressure: 3.1 torr; Temp: $-4.5{ }^{\circ} \mathrm{C}$; humidity: $92.3 \%$ ) 

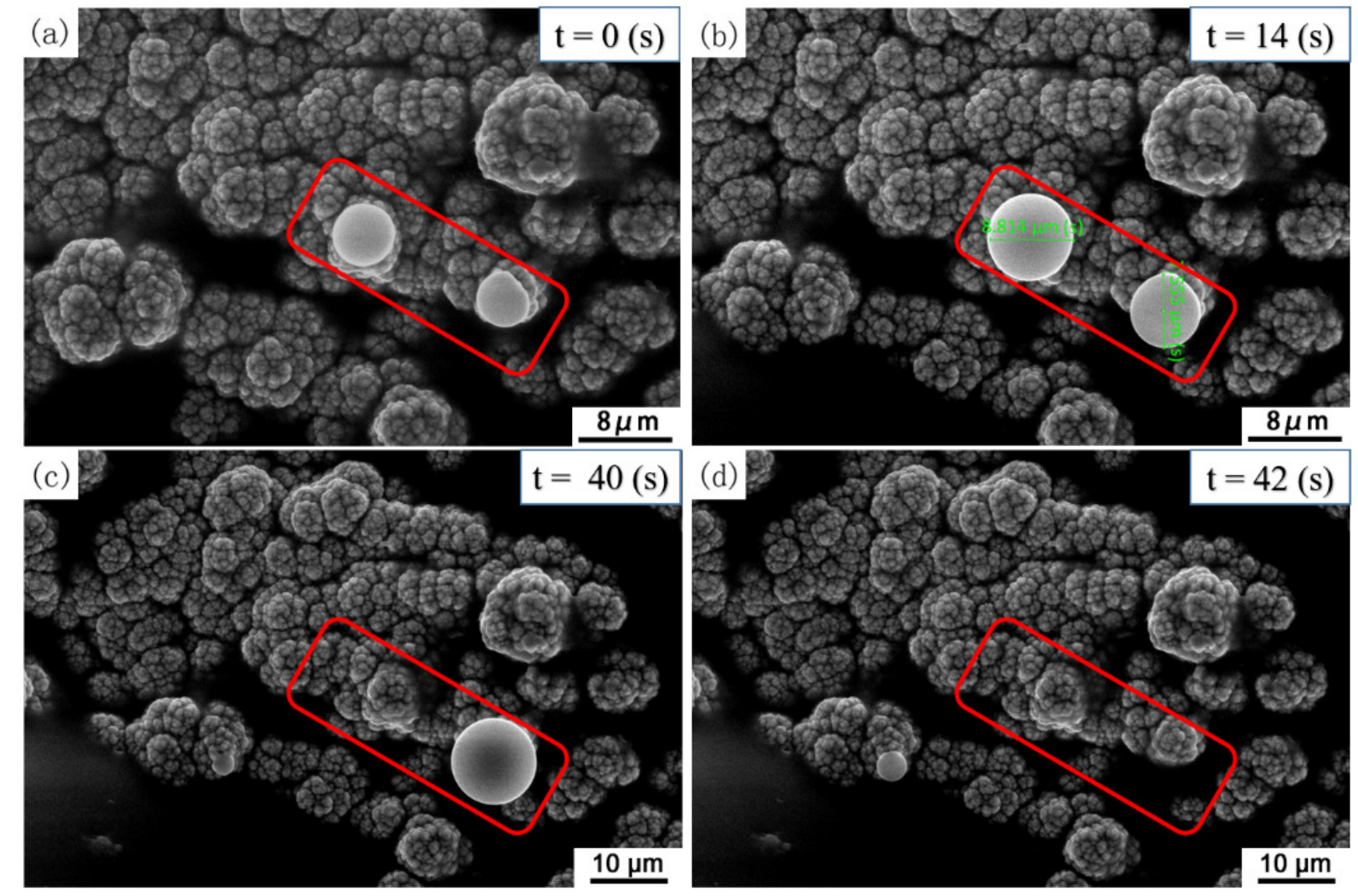

Figure 10 Water condensation and gathering process on electro-deposited $\mathrm{Ni}-\mathrm{Cu}-\mathrm{P}$ coating after being stored in ambient air (Pressure: 4.7 torr; Temp: $1.0{ }^{\circ} \mathrm{C}$; humidity: $95.0 \%$ ) 

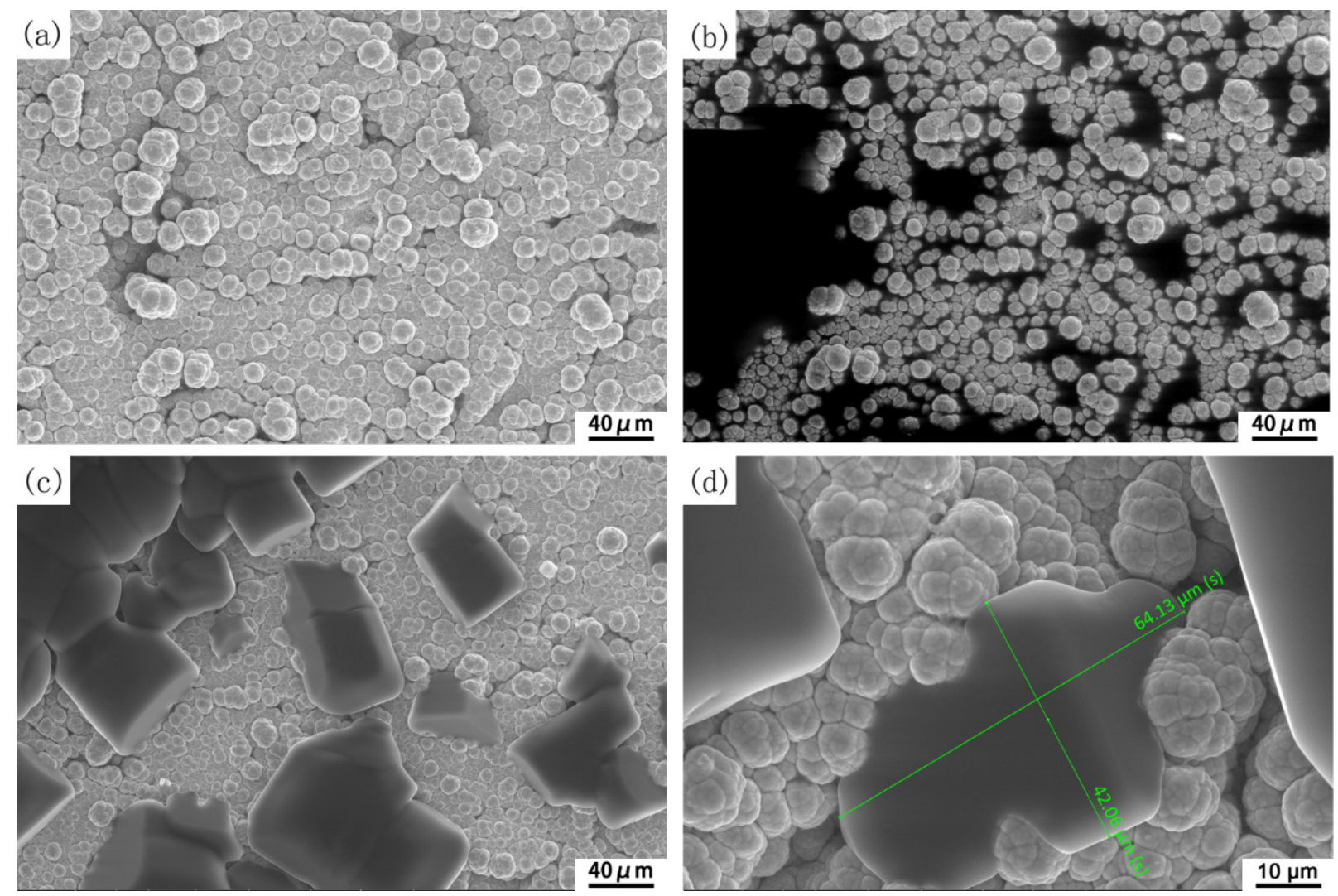

Figure 11 (a) (b) Water condensation and gathering process on electro-deposited Ni-Cu-P coating after plasma cleaning (Pressure: 5.3 torr; Temp: $2.5{ }^{\circ} \mathrm{C}$; humidity: $96.7 \%$ ); (c) (d) Ice formation process on electro-deposited Ni-Cu-P coating after plasma cleaning (Pressure: 2.6 torr; Temp: $-6.6{ }^{\circ} \mathrm{C}$; humidity: $\left.94.0 \%\right)$ 


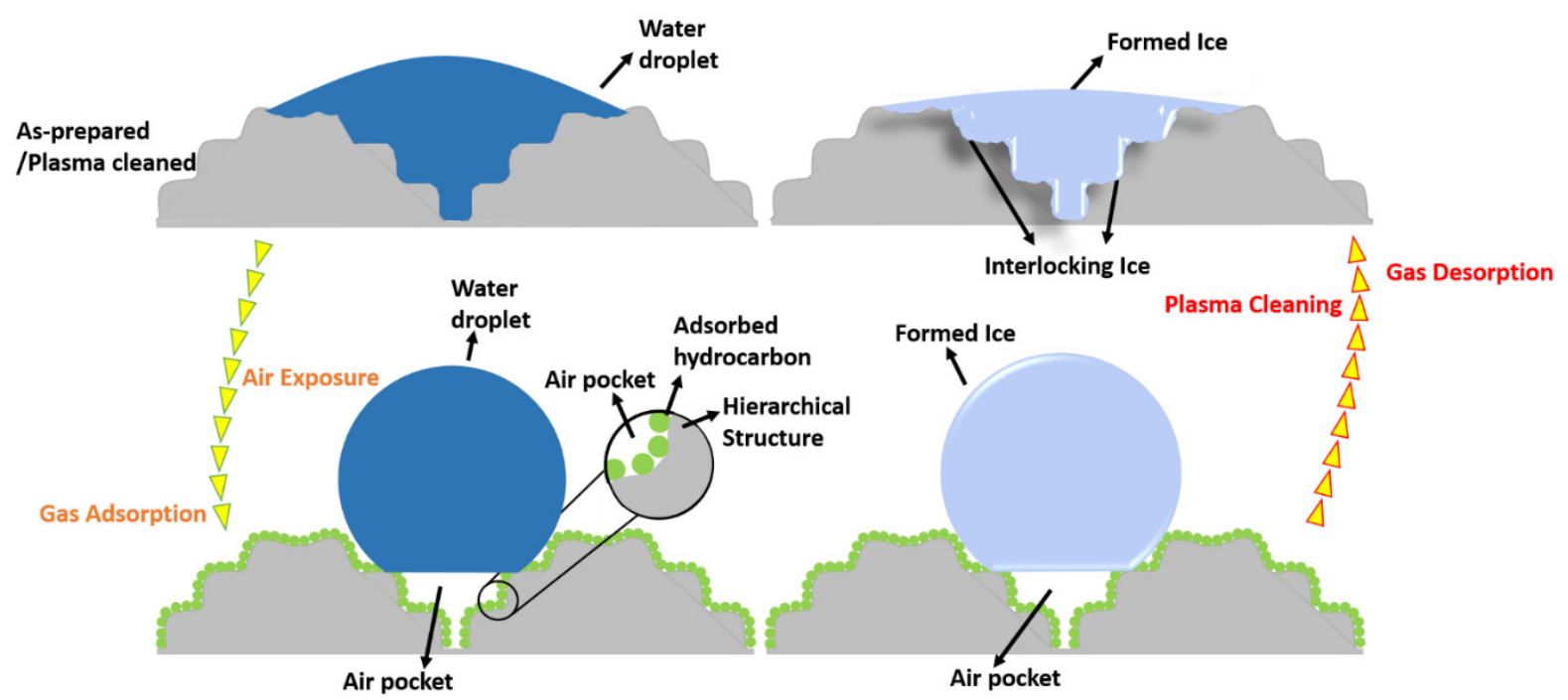

Figure 12 Schematic of the behaviour of water droplet and formed ice of the $\mathrm{Ni}-\mathrm{Cu}-\mathrm{P}$ coating 